\title{
Plasmaspheric electron content in the GPS ray paths over Japan under magnetically quiet conditions at high solar activity
}

\author{
N. Balan ${ }^{1,2 *}$, Y. Otsuka ${ }^{1}$, T. Tsugawa ${ }^{3}$, S. Miyazaki ${ }^{4}$, T. Ogawa $^{1}$, and K. Shiokawa ${ }^{1}$ \\ ${ }^{1}$ STE Laboratory, Nagoya University, 3-13 Honohara, Toyokawa, Aichi 442-8507, Japan \\ ${ }^{2}$ Department of Applied Mathematics, University of Sheffield, Sheffield S3 7RH, England \\ ${ }^{3}$ Graduate School of Science, Kyoto University, Kyoto 606-8502, Japan \\ ${ }^{4}$ Geographical Survey Institute, Tsukuba, Ibaraki 305-0811, Japan
}

(Received October 31, 2000; Revised February 22, 2001; Accepted March 19, 2001)

\begin{abstract}
Vertical total electron content (GPS-TEC) data obtained from the dual-frequency GPS receiver network (GEONET) in Japan are compared with those calculated using the Sheffield University plasmasphere-ionosphere model (SUPIM). The model is also used to estimate the electron content in the plasmaspheric sections of GPS ray paths for the three seasons of high solar activity $(\mathrm{F} 10.7=165)$ under magnetically quiet conditions. According to the estimates, the plasmaspheric sections of vertical GPS ray paths over Japan at altitudes above the $\mathrm{O}^{+}$to $\mathrm{H}^{+}$transition height and above the upper altitude $(2500 \mathrm{~km})$ of Faraday rotation contain up to 11 and 9 TEC units $(1$ TEC unit $=10^{16}$ electrons $\mathrm{m}^{-2}$ ) of free electrons, respectively. The free electrons present above the Faraday rotation altitude can cause propagation errors of up to $4.9 \mathrm{~ns}$ in time delay and $1.6 \mathrm{~m}$ in range at the GPS L1 (1.57542 GHz) frequency. The plasmaspheric electron content, PEC, changes appreciably with season and latitude and very little with the time of the day. However, the percentage contribution of PEC to GPS-TEC changes most significantly with the time of the day; the contribution varies from a minimum of about $12 \%$ during daytime at equinox to a maximum of about $60 \%$ at night in winter.
\end{abstract}

\section{Introduction}

Global positioning system (GPS), the most modern navigation system, has satellites in orbits at an altitude of about $20200 \mathrm{~km}$, inclined at $55^{\circ}$ to the equatorial plane, which transmit navigation signals at two frequencies $1.57542 \mathrm{GHz}$ (L1) and $1.22760 \mathrm{GHz}$ (L2). Reception of the signals from four satellites enables the position of the observer to be determined. However, the accuracy of the positioning can be affected by propagation errors in time delay and range caused by the ionization (or free electrons) present between the satellites and receivers. These errors are taken care of by two different methods. One method uses dual-frequency receivers which receive signals at both frequencies and thus allowance is automatically made for the variations of the ionization. But, these receivers are highly expensive. The other method, which is inexpensive, uses single frequency receivers with appropriate corrections for the effects of the ionization.

The total amount of free electrons present in the vertical GPS ray path, called vertical total electron content (GPSTEC), is composed mainly of ionospheric electron content, IEC, and partly of plasmaspheric electron content, PEC. Values of IEC have been measured using satellite beacons (Evans, 1977; Davies, 1980; Titheridge, 1973; Balan et al.,

*On leave from the Department of Physics, University of Kerala, India.

Copy right (c) The Society of Geomagnetism and Earth, Planetary and Space Sciences (SGEPSS); The Seismological Society of Japan; The Volcanological Society of Japan; The Geodetic Society of Japan; The Japanese Society for Planetary Sciences.
1993), and empirical models have been developed. Models like that of Klobuchar (1987) have been incorporated into single frequency GPS receivers to compensate for the gross variations of IEC. However, little is known about PEC, except for some determinations obtained using the difference between the electron content measured by the differential phase shift techniques and that measured by the Faraday rotation technique using radio beacons on geostationary satellites (Kersley et al., 1978; Ogawa et al., 1980). Recently, Kimura et al. (1997) reported determinations of PEC by applying ray-tracing techniques to Omega navigational signals. These determinations show that the electron content in the plasmaspheric section of the GPS ray paths can at times be a significant fraction of the total content. Doherty et al. (1992) presented determinations of PEC along actual GPS ray paths, obtained from the difference between the GPS and Faraday rotation electron contents. Recently, Lunt et al. (1999) estimated the values of PEC in the GPS ray paths at altitudes above $1100 \mathrm{~km}$ in European and American sectors. Gallagher et al. (1988) presented an empirical model of the plasmasphere.

The present study is aimed at estimating the values of PEC along the GPS ray paths in Asian sector, especially over Japan. The importance of the study is illustrated through a simple sketch in Fig. 1, which shows the diurnal variations of the GPS-TEC over Japan and the corresponding propagation errors, i.e., 


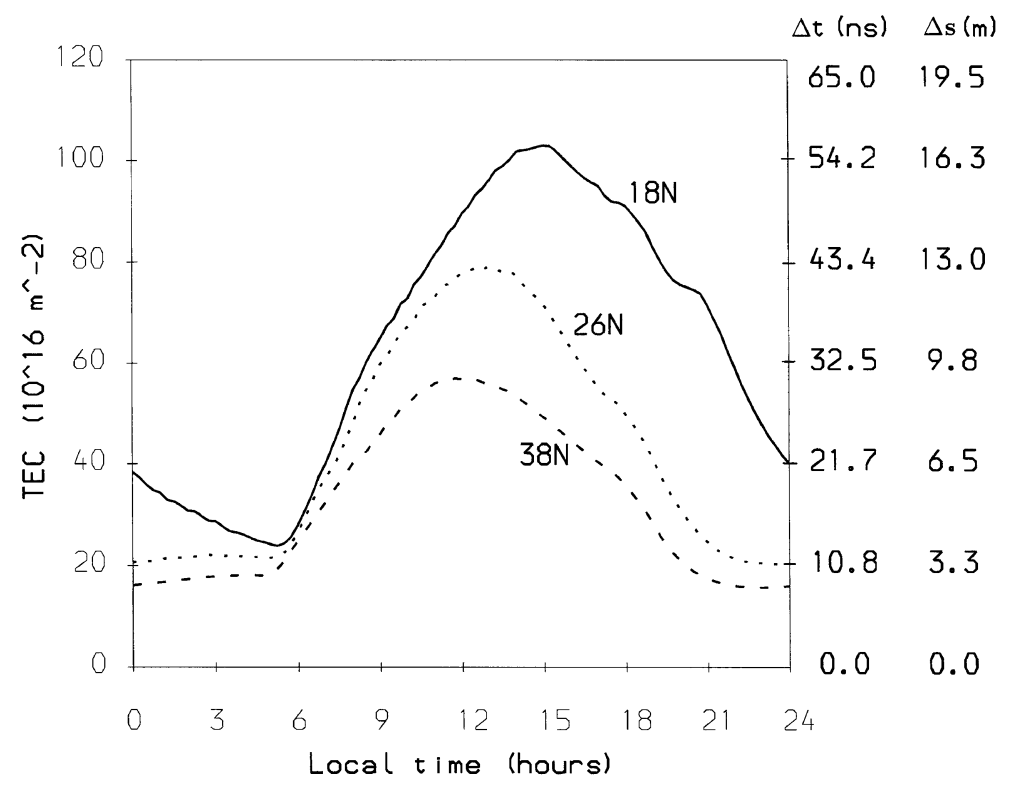

Fig. 1. Local time variations of model GPS-TEC at the southern, mid and northern magnetic latitudes of Japan at high solar activity; the corresponding propagation errors (time delay $\Delta t$ in nano seconds and range error $\Delta s$ in meters) at the L1 GPS frequency are also shown.

$$
\begin{aligned}
& \text { time delay } \Delta t=\left(\frac{40.3}{c f^{2}}\right) \text { [GPS-TEC] } \\
& \text { range error } \Delta s=(c \Delta t)
\end{aligned}
$$

where GPS-TEC $=\int N d s ; N$ is electron density $\left(\mathrm{m}^{-3}\right)$ along the ray path and $d s$ is an element of length $(\mathrm{m})$ along the path, $f$ is frequency $(\mathrm{Hz})$ and $c$ is free space velocity of light $\left(\mathrm{m} \mathrm{s}^{-1}\right)$. As shown by Fig. 1, the total amount of free electrons (TEC) present over the entire length of the vertical GPS ray paths can cause time delays of up to 55 $\mathrm{ns}$ and range errors of up to $16 \mathrm{~m}$ in GPS navigation at the L1 frequency. However, in single frequency L1 GPS receivers, compensation has been made only for the free electrons (IEC) present in the ionospheric section of the ray paths because the amount of free electrons (PEC) present in the plasmaspheric section is not known. As mentioned above, the present study estimates the values of PEC over Japan for the first time.

Absolute values of GPS-TEC derived from the carrier phase delays and pseudoranges of the GPS signals (L1 and L2) recorded by the GPS network (GEONET) in Japan (Otsuka et al., 2002) are compared with those calculated using the Sheffield University plasmasphere ionosphere model, SUPIM (Bailey and Balan, 1996; Bailey et al., 1997). The model is then used to calculate values of GPSTEC and the corresponding IEC, which, in turn, are used to estimate PEC (=TEC - IEC). The $\mathrm{O}^{+}$to $\mathrm{H}^{+}$transition height is taken as the base of the plasmasphere. The absolute and percentage contributions of PEC to GPS-TEC are presented as functions of local time and latitude for the three seasons in 1999.

\section{Estimation of GPS-TEC}

The Geographical Survey Institute of Japan has installed a network of about 1000 dual-frequency GPS receivers
(GEONET) in Japan with a mean distance of approximately $25 \mathrm{~km}$ between the receivers. The main purpose of the network is to monitor crustal deformation; the network also provides information about water vapor and electron content. The phase delays and pseudoranges of the GPS signals recorded by the network have been used to derive relative values of TEC. Saito et al. (1999) have presented a twodimensional map of TEC perturbations over Japan using this network.

The absolute values of TEC used in the present study are derived from the GEONET records of the carrier phase delays and pseudoranges of the GPS signals following a method developed by Lanyi and Roth (1988). The instrumental biases inherent in the receivers and transmitters are taken care of by using a least square fitting method (Otsuka et al., 2002). The derived slant TEC is converted to the equivalent vertical TEC (GPS-TEC) by multiplying by a projection factor. The GPS-TEC derived by this method gives electron content up to a certain altitude; there is an inherent ambiguity in specifying the upper altitude (see Otsuka et al., 2002). However, comparisons with other data have shown that the upper altitude is well above $1000 \mathrm{~km}$. For example, the electron content obtained from the MU radar electron density profiles integrated up to $1000 \mathrm{~km}$ altitude (figure not shown) has been found to be less than GPSTEC by over 10 TEC units $\left(1\right.$ TEC unit $=10^{16}$ electrons $\mathrm{m}^{-2}$ ), the values of PEC obtained from the difference between differential phase shift and Faraday rotation electron contents have been found to be up to 6 TEC units (Ogawa et al., 1980), and the values of PEC estimated between about $1000 \mathrm{~km}$ and GPS altitude is up to 11 TEC units (present study). These comparisons show that the upper altitude of GPS-TEC derived from Otsuka et al. (2002) method is well above $1000 \mathrm{~km}$. 


\section{Model Calculations}

As mentioned above, the model values of TEC, IEC and PEC are calculated by the physical model, the Sheffield University plasmasphere-ionosphere model (SUPIM, Bailey and Balan, 1996). In SUPIM, coupled time-dependent equations of continuity, momentum and energy balance are solved by an implicit finite difference scheme along closed dipole magnetic field lines between base altitudes of about $120 \mathrm{~km}$ in conjugate hemispheres to give values for the concentrations, field-aligned fluxes and temperatures of the $\mathrm{O}^{+}$, $\mathrm{H}^{+}, \mathrm{He}^{+}, \mathrm{N}_{2}^{+}, \mathrm{O}_{2}^{+}$and $\mathrm{NO}^{+}$ions, and the electrons at a discrete set of points along the field lines. The modeling procedure followed is the same as that described elsewhere (Balan et al., 1994; Balan and Bailey, 1995). The model equations are solved along 200 eccentric-dipole magnetic field lines distributed with apex altitude from 150 to $30000 \mathrm{~km}$ with the number of points along the field lines increasing with apex altitude from 201 to 401 . The model calculations are for the longitude of the MU radar $\left(135^{\circ} \mathrm{E}, 35^{\circ} \mathrm{N} ; 26^{\circ} \mathrm{N}\right.$ mag. lat.) and for the three seasons in 1999.

Neutral wind velocity in the magnetic meridian is an important parameter that determines the ionospheric electron density and ionosphere-plasmasphere coupling at mid latitudes. The neutral wind velocity, which varies with altitude and latitude, is determined from the meridional and zonal wind velocities given by HWM90, the best available wind model (Hedin et al., 1991). However, the wind velocities given by the model are known to differ significantly from observations, especially over Japan. For the present study, the model meridional winds in the northern hemisphere are modified to approximate the MU radar measured winds following a method adopted earlier (Balan et al., 1998). In the modification the model meridional wind velocities in the northern hemisphere at night (2100-0400 LT) are reduced by $65 \%$ in summer, $60 \%$ at equinox and $20 \%$ in winter. Winds in all seasons are retarded by 2 hours during 0600 2400 LT and linear interpolations are used for the periods in between; no modification is made for the meridional winds in the southern hemisphere and zonal winds in either hemisphere.

The ionospheric $\mathbf{E} \times \mathbf{B}$ drift velocities are obtained directly from the MU radar measurements. The northward perpendicular drifts measured by the MU radar (Oliver et $a l ., 1993)$ are scaled to the magnetic equator and used for the field line with apex at $1800 \mathrm{~km}$; an appropriate Jicamarca drift (by season and solar activity) (Fejer et al., 1991) is used for field lines with apex less than $450 \mathrm{~km}$; no drift is used for field lines at apex higher than $20000 \mathrm{~km}$; and linear interpolations are used for the field lines at intermediate apex altitudes. The field line with apex altitude $1800 \mathrm{~km}$ intersects the $F$ region over the MU radar. The zonal $\mathbf{E} \times \mathbf{B}$ drift is neglected as it has little effect.

The concentrations and temperatures of the neutral gases are taken from MSIS86 thermospheric model (Hedin, 1987), solar EUV fluxes from the EUV94 solar EUV flux model (a revised version of the EUV91 solar EUV flux model, Tobiska, 1991) and photoelectron heating rates are adopted from the model developed by Richards and Torr (1988). The remaining model inputs such as photoionization and photoabsorption cross sections, chemical reaction rates, heat- ing and cooling rates and collision frequencies used in the SUPIM model have been described elsewhere (Bailey and Balan, 1996).

\section{Results and Discussion}

As mentioned above, the model calculations are for the longitude $\left(135^{\circ} \mathrm{E}\right)$ of the $\mathrm{MU}$ radar and for the three seasons in 1999 when solar activity was high $(\mathrm{F} 10.7=165)$; magnetic activity is considered quiet $(\mathrm{Ap}=4)$. The calculations are repeated from 3 to 16 iteration days (for the lowest to the highest field line) so that the model outputs on the last iteration day represent an ionosphere-plasmasphere system with a filled plasmasphere, which corresponds to the situation after a series of magnetically quiet days (Carpenter and Park, 1973; Chi et al., 2000). The model outputs on the last iteration day are regridded at intervals of $25 \mathrm{~km}$ in altitude up to GPS altitude, $2^{\circ}$ in latitude to cover the latitude of Japan and $15 \mathrm{~min}$ in local time for 24 hours.

Figure 2 shows a comparison of the vertical electron density profiles at noon and midnight in three seasons. As shown, unlike in the ionosphere, electron density in the plasmasphere does not change with time of the day, indicating a filled plasmasphere. Also, the seasonal anomaly with lowest daytime electron density in summer observed near and below the ionospheric peak (Rishbeth and Setty, 1961) does not exist in the topside ionosphere and plasmasphere, which agrees with MU radar observations (Balan et al., 1997). In fact, the electron density in the plasmasphere is highest in summer (Fig. 2), which results mainly from the summer to winter interhemispheric neutral winds. In the summer side, the wind pushes the ionosphere up and thus enhances the $\mathrm{O}^{+}$ to $\mathrm{H}^{+}$charge exchange while in the winter side, the wind pulls the ionosphere down and reduces the charge exchange. The net result is a high $\mathrm{H}^{+}$population in the summer side

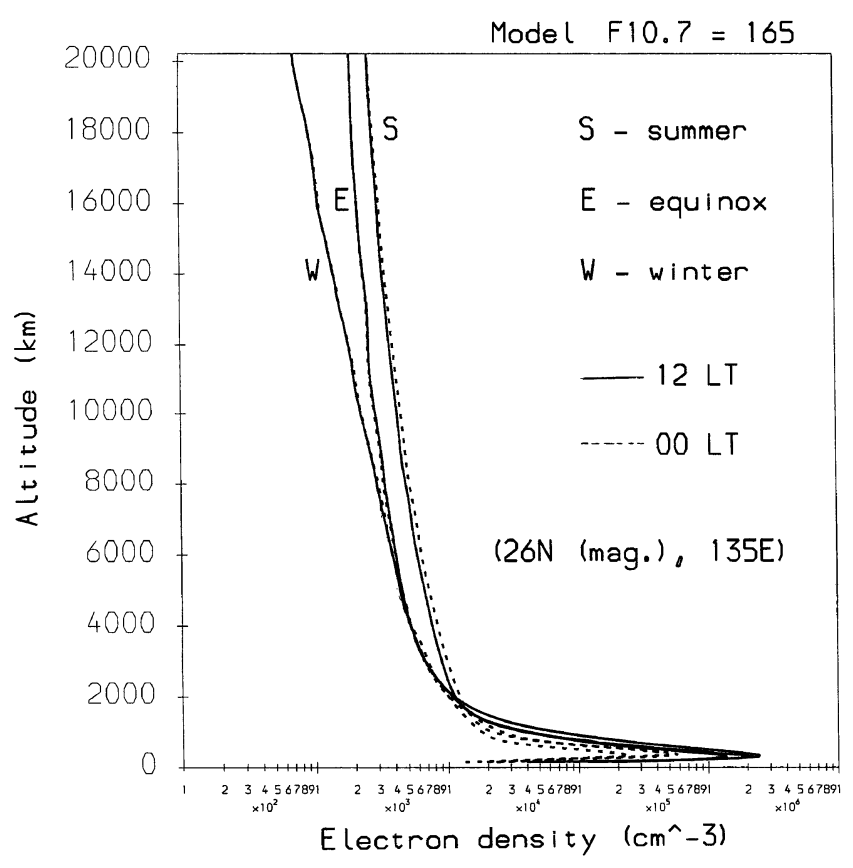

Fig. 2. Altitude profiles of model electron density profiles up to GPS altitude at noon and midnight in winter, summer and equinox. 
and low $\mathrm{H}^{+}$population in the winter side of the plasmaspheric reservoir. The model plasmaspheric electron density profiles (Fig. 2) are found to agree reasonably with those measured by the Akebono satellite (Kimura et al., 2000).

The electron density profiles (for example, Fig. 2) are integrated up to GPS altitude for TEC and up to the base of the plasmasphere for IEC at 15 minutes intervals. The difference between the two gives PEC (=TEC-IEC). There has been some arbitrariness in selecting the base altitude of the plasmasphere (Lunt et al., 1999). For the present study, the diurnal mean $\left[\mathrm{O}^{+}\right]$to $\left[\mathrm{H}^{+}\right]$transition height is taken as the base of the plasmasphere. The transition height at noon and midnight for summer is shown in Figs. 3(a) and 3(b) which contain altitude profiles of the important ions $\left(\mathrm{H}^{+}, \mathrm{O}^{+}\right.$and $\left.\mathrm{He}^{+}\right)$and electrons. As shown by Figs. 3(a) and $3(\mathrm{~b})$, the transition height decreases from about 1350 $\mathrm{km}$ at noon (Fig. 3(a)) to $780 \mathrm{~km}$ at midnight (Fig. 3(b)). The diurnal mean transition height is estimated at around $1150 \mathrm{~km}$ in summer, $950 \mathrm{~km}$ in winter and $1100 \mathrm{~km}$ at equinox. PEC estimated in the present paper represents the electron content above these altitudes. The electron content above the upper altitude of Faraday rotation $(2500 \mathrm{~km})$ is also estimated.

The diurnal variations of the measured (dotted curve) and modeled GPS-TEC are compared in Fig. 4(a) for one day (10 May 1999) in summer; model TEC is shown for two cases, one modeled using the modified HWM90 neutral wind (thick solid curve) and the other modeled using the unmodified HWM90 neutral wind (thin dashed curve). As shown by the comparison, the TEC modeled with the unmodified HWM90 neutral wind is much greater than the measured TEC, indicating the inadequacy of this model wind for Japan sector. However, the TEC modeled with a modified HWM90 wind agrees reasonably with the measured TEC. Both values increase from a minimum of about 20 TEC units just before sunrise, reach a maximum of about 50 TEC units just after noon and then decrease to the nighttime minimum.

Figure 4(a) also includes the variations of IEC integrated up to the base of the plasmasphere, $1150 \mathrm{~km}$ in this case. The IEC (thin solid curve) is less than GPS-TEC (thick solid curve) by up to 11 TEC units, which gives PEC. The electron content integrated up to $2500 \mathrm{~km}$ altitude, representing the Faraday rotation ionospheric electron content (Titheridge, 1972), is also shown in Fig. 4(a) (dot-dashed curve). The electron content above the Faraday rotation altitude has values up to 9 TEC units. The difference between the dot-dashed curve and thin curve (Fig. 4(a)) gives about 2 TEC units of free electrons between the $\mathrm{O}^{+}-\mathrm{H}^{+}$transition height and the upper altitude of Faraday rotation.

A comparison of the latitude variations of the measured and modeled GPS-TEC at local noon and midnight is shown in Fig. 4(b) for the day in summer. In Fig. 4(b), the measured TEC corresponds to the data averaged over the longitude of Japan $\left(128^{\circ} \mathrm{E}\right.$ to $\left.146^{\circ} \mathrm{E}\right)$ while the modeled TEC is for the longitude of the MU radar. There is reasonable agreement between the measured and modeled TEC (Figs. 4(a) and $4(\mathrm{~b}))$. The difference existing between the two is due to several factors. For example, the measured data does not represent the TEC up to the GPS altitude, the vertical TEC

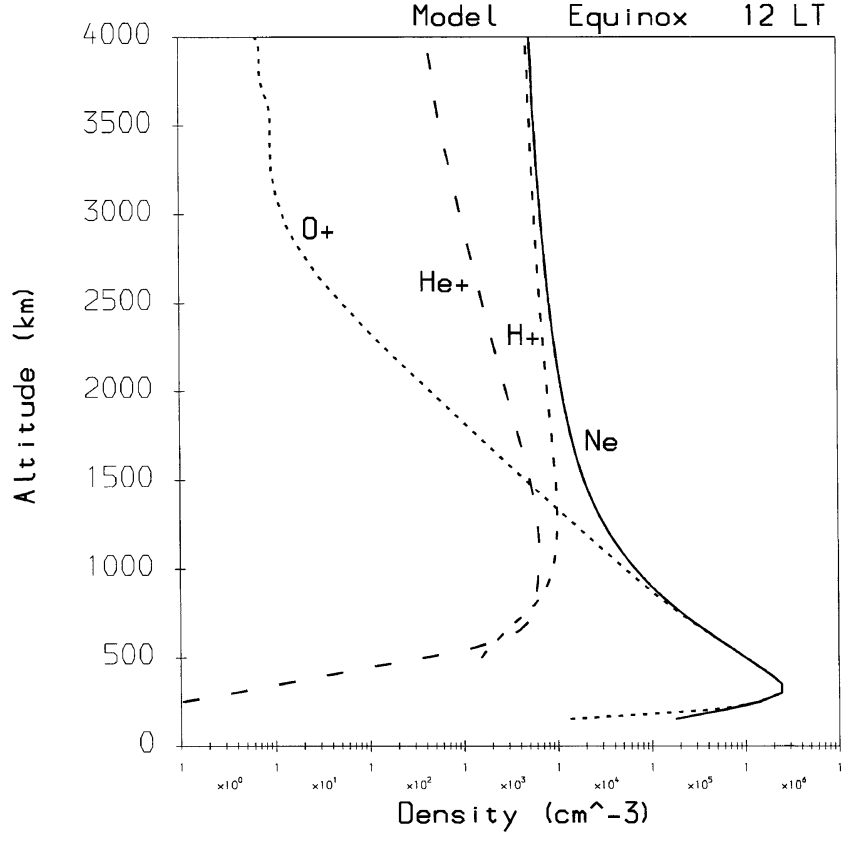

Fig. 3(a). Altitude profiles of important ions and electrons at noon in one season (summer) showing the $\mathrm{O}^{+}$to $\mathrm{H}^{+}$transition height taken as the base of the plasmasphere.

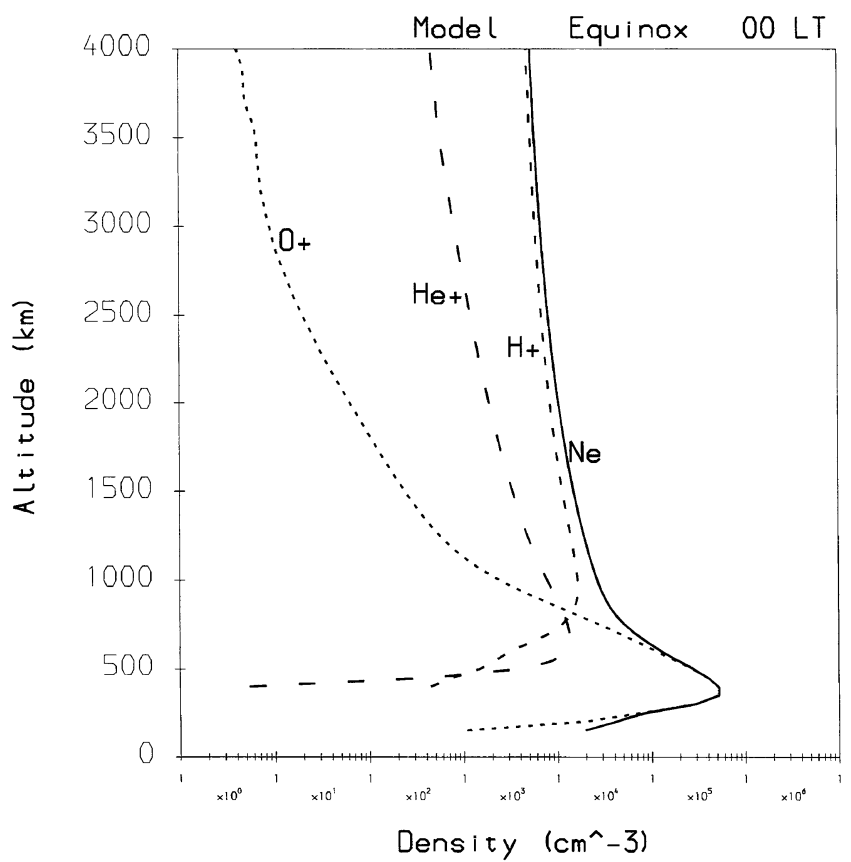

Fig. 3(b). Same as Fig. 3(a) but for midnight.

is obtained from the measured slant TEC using a projection factor, the model data does not include the electron content at altitudes below $150 \mathrm{~km}$, and there could be uncertainties in the model inputs. Also, while the model data represents a completely filled plasmasphere, the measured data may not correspond to a completely filled plasmasphere.

As discussed above, model GPS-TEC agrees reasonably with the measured TEC (Fig. 4(a)) when suitable neutral wind velocities are used in the model calculations. Follow- 


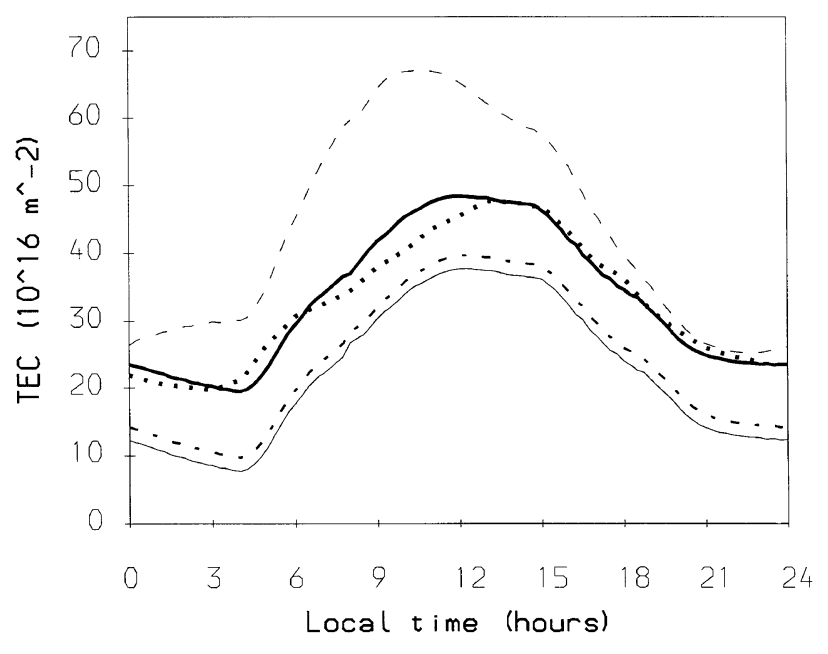

Fig. 4(a). Comparison of the local time variations of the measured (dotted curve) and modeled GPS-TEC; the TEC modeled using modified (thick solid curve) and unmodified (thin dashed curve) HWM90 neutral winds are shown; also shown are the IEC modeled with modified HWM90 neutral winds and integrated up to $1150 \mathrm{~km}$ (thin solid curve) and up to $2500 \mathrm{~km}$ (dot-dashed curve) altitudes.

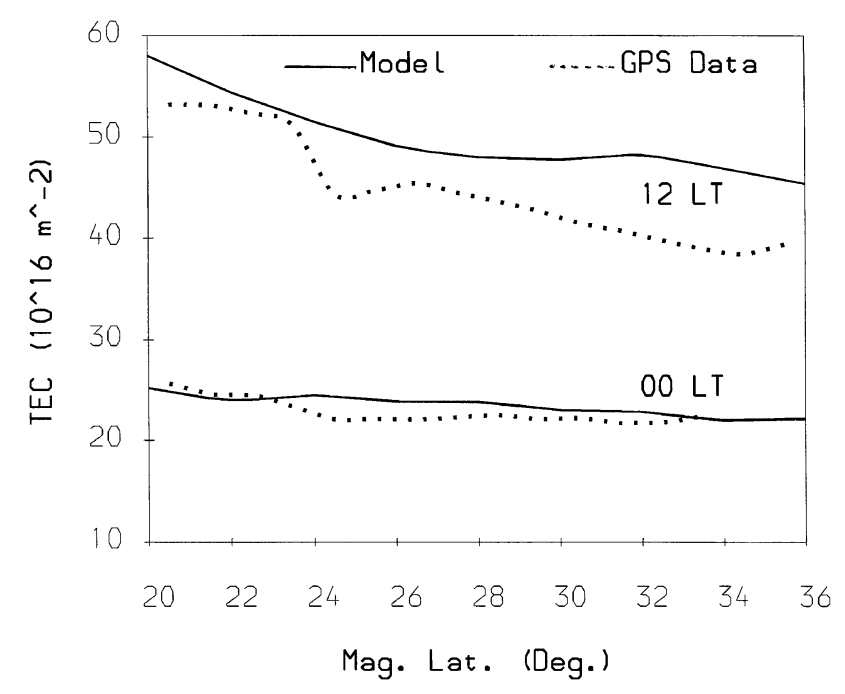

Fig. 4(b). Comparison of the latitude variations of measured (dotted curve) and modeled (thick solid curve) GPS-TEC at noon and midnight.

ing that procedure, model values of TEC and IEC are calculated for the three seasons using appropriate neutral wind patterns, described in Section 3. The diurnal variations of the resulting TEC (solid curves) and IEC (dashed curves) for the three seasons are shown in the top panels of Fig. 5. A comparison of the values of TEC and IEC in different seasons reveals that though seasonal and semiannual components exist in these parameters, their seasonal anomaly (higher values during daytime in winter than in summer) has been greatly reduced compared to the anomaly in peak electron density (figure not shown); that is due to the disappearance of the anomaly in the topside ionosphere and plasmasphere (Balan et al., 1998).

The diurnal variations of PEC above the $\mathrm{O}^{+}-\mathrm{H}^{+}$transition height for the three seasons, obtained from the difference between TEC and IEC, are shown in the bottom panels of Fig. 5 (solid curves). As shown, unlike TEC and IEC, PEC undergoes an annual variation with highest values (about 11 TEC units) in summer and lowest values (about 7 TEC units) in winter; the values in equinox (about 9 TEC units) fall in between. The percentage of PEC to GPS-TEC varies with the time of the day while the absolute PEC does not change significantly. That is illustrated by the dotted curves in the bottom panel of Fig. 5, which shows the diurnal variations of the percentage contribution of PEC to GPS-TEC. As shown, the contribution of PEC to GPS-TEC becomes most significant at night in all seasons. The contribution ranges from a minimum of about $12 \%$ at noon at equinox to a maximum of about $60 \%$ at night in winter and before sunrise in summer. The contribution in winter and summer reaches a peak just before sunrise when TEC reduces to its minimum.

Figure 6 displays the latitude variations of the absolute (top panel) and the percentage (bottom panel) contribution of PEC to GPS-TEC at local noon and midnight in three seasons. As shown in the top panel, the absolute contribution of PEC to GPS-TEC (top panel) decreases with increasing latitude in all seasons, with maximum decrease in winter and minimum decrease in summer. Considering all seasons together, PEC in the latitude of Japan decreases from a maximum of about $11 \mathrm{TEC}$ units at the southern end $\left(20^{\circ} \mathrm{N}\right.$ mag. lat.) in summer to a minimum of about 5 TEC units at the northern end $\left(36^{\circ} \mathrm{N}\right.$ mag. lat.) in winter, giving an overall annual change of about 6 TEC units. The day-to-night change of PEC, which slowly reduces with increasing latitude, is less than 1 TEC unit in all seasons. The percentage contribution of PEC to GPS-TEC (bottom panel of Fig. 6) remains almost constant with latitude, except for the night at equinox when the contribution is slightly low at the southern end.

According to the estimates presented above, the plasmaspheric section of the vertical GPS ray paths over Japan at altitudes above the $\mathrm{O}^{+}-\mathrm{H}^{+}$transition height $(950-1150 \mathrm{~km}$ ) contains up to 11 TEC units of free electrons during magnetically quiet periods at high solar activity $(\mathrm{F} 10.7=165)$. PEC also decreases from a maximum of about 11 TEC units at the southern end of Japan $\left(20^{\circ} \mathrm{N}\right.$ mag. lat.) in summer to a minimum of about 5 TEC units at the northern end $\left(36^{\circ} \mathrm{N}\right.$ mag. lat.) in winter, giving an overall annual change of about 6 TEC units. The estimates also show that the absolute value of PEC in a filled plasmasphere is almost independent of local time.

The present estimates of PEC over Japan agree reasonably with those determined earlier by Ogawa et al. (1980). They measured up to $6 \mathrm{TEC}$ units of PEC at $25^{\circ} \mathrm{N}$ magnetic latitude in Japan and along slant ray paths at altitudes above the upper altitude of Faraday rotation in the winter of medium solar activity (1978). The present estimates under similar conditions at high solar activity give about 7 TEC units of vertical PEC above the $\mathrm{O}^{+}-\mathrm{H}^{+}$transition height (see Figs. 5 and 6). The electron content present between the $\mathrm{O}^{+}$$\mathrm{H}^{+}$transition height (950) and the upper altitude of Faraday rotation (about $2500 \mathrm{~km}$ ), about 2 TEC units, seems to be almost equal to the excess electron content present in the slant ray paths above the upper altitude of Faraday rotation. The estimated PEC over Japan also decreases with increasing latitude (Fig. 6) as expected from the latitude variation 

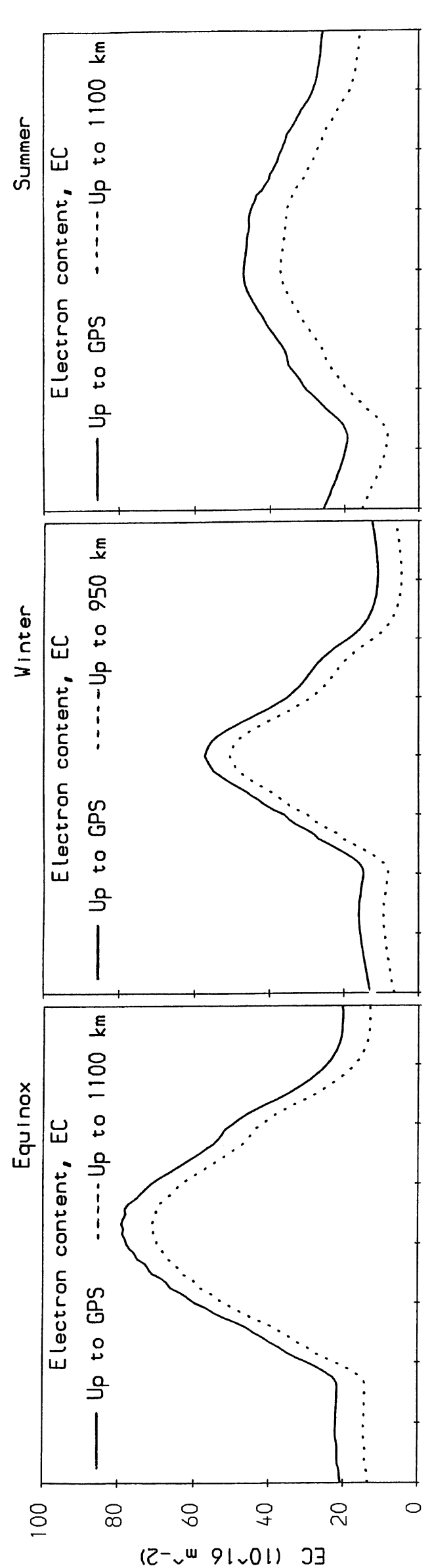

(\%) J Jd
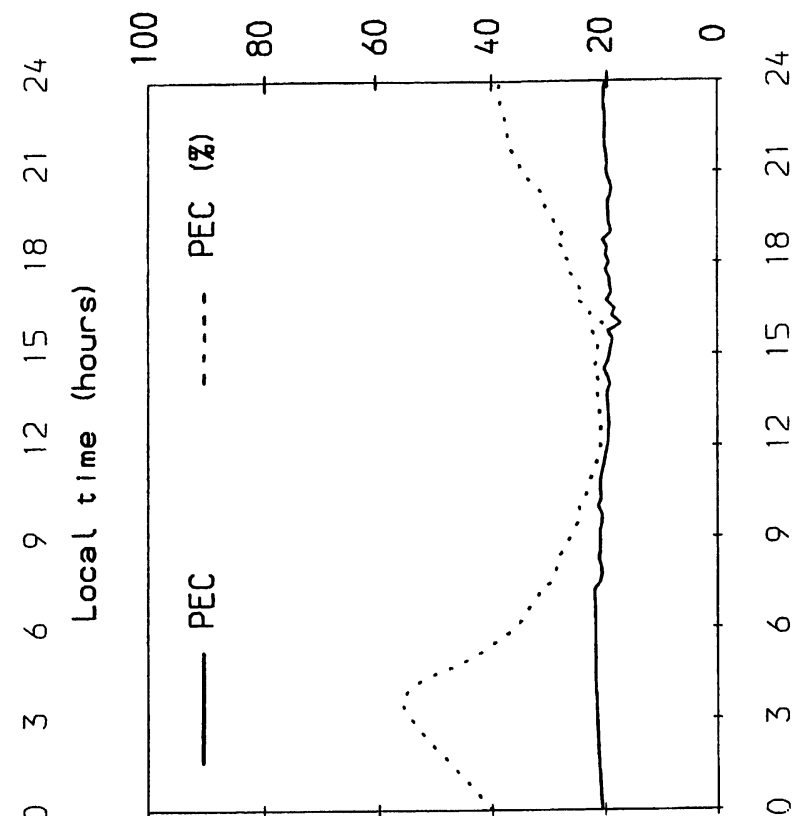

$\bar{\sim}$

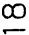

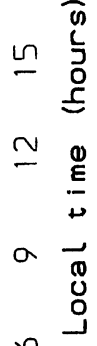

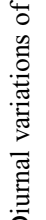

$\bar{\sim}$

$\stackrel{\infty}{\circ}$

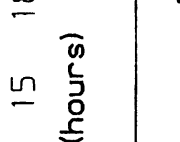

$\simeq$

a

㟧

$m$

$\bar{\sim}$

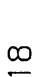

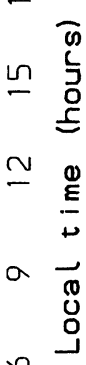

m

○

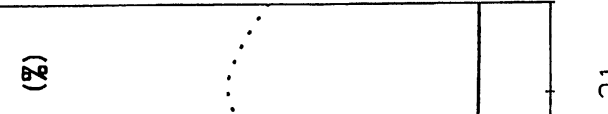

$M$

○

$\bar{\sim}$

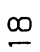

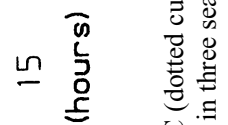

$\simeq \stackrel{\boldsymbol{\omega}}{\mathrm{E}}$

म

○

$0^{-1}$

픙

$m$ m

角.

o

$\bar{v}$

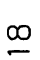

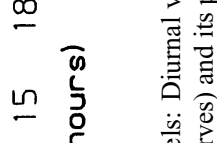

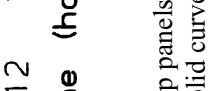

$\simeq \stackrel{\boldsymbol{E}}{\boldsymbol{E}} \quad$

a

|

o 

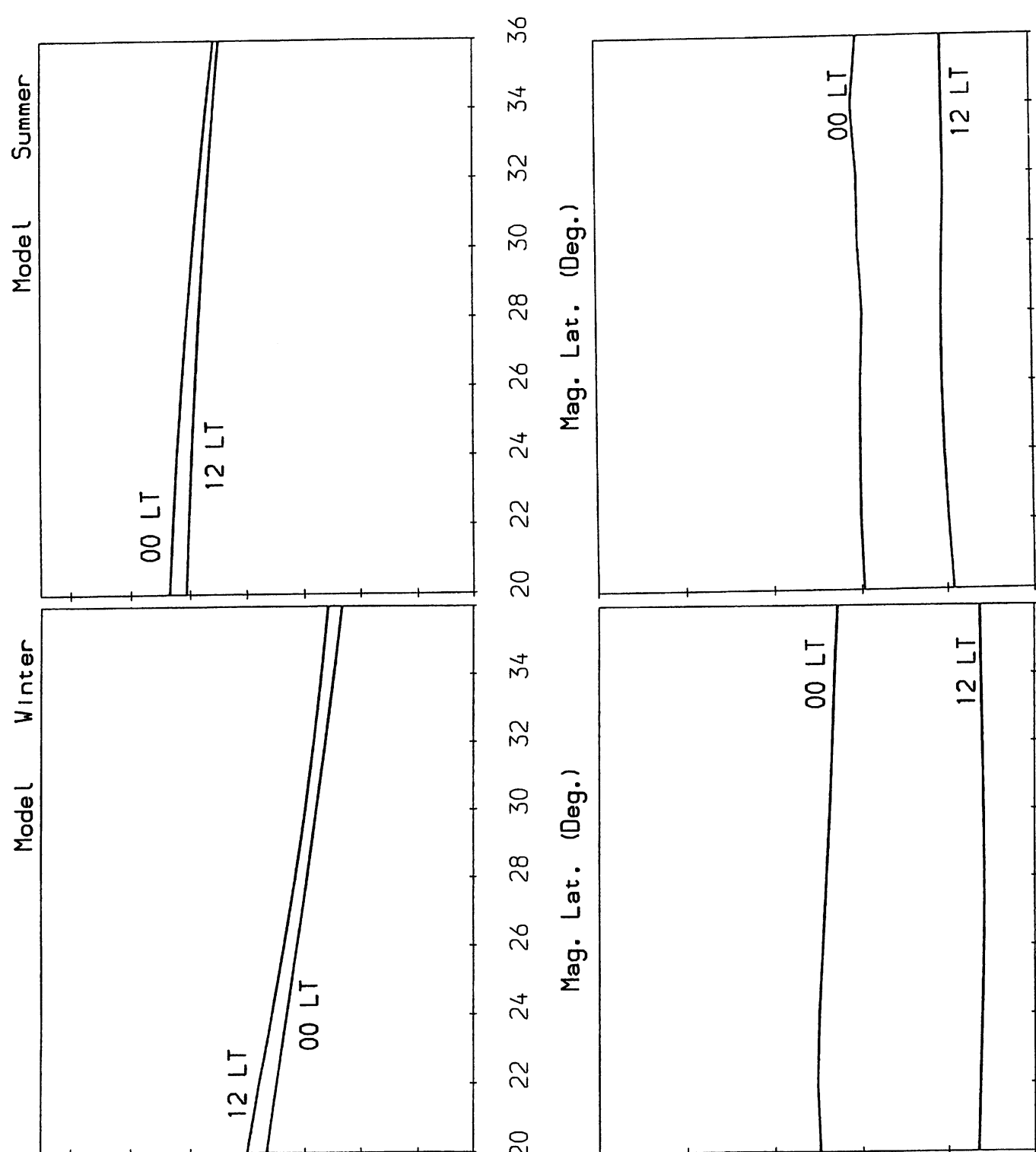

i̊

i

N

요

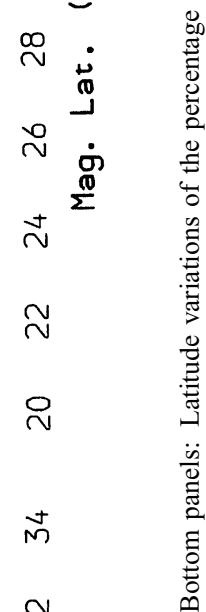

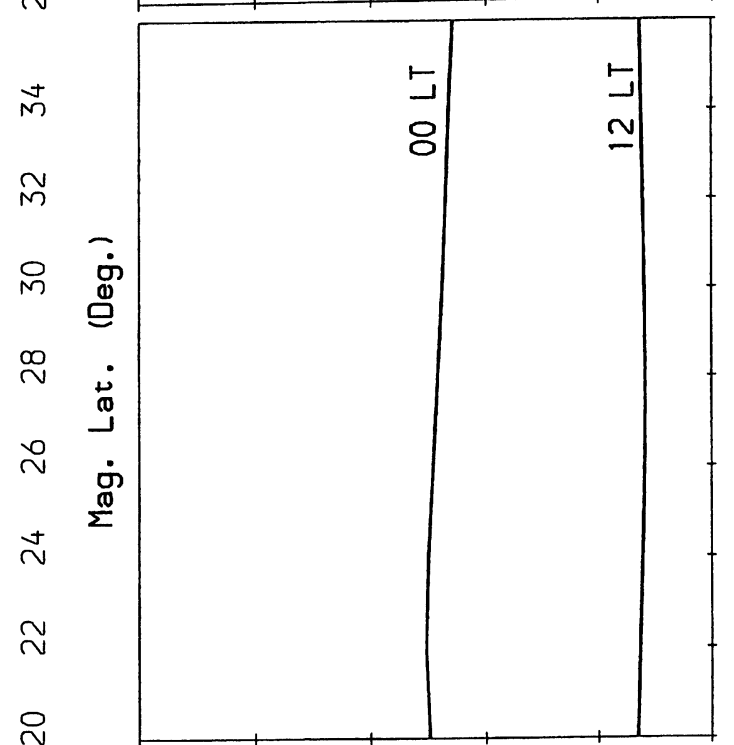

ำ
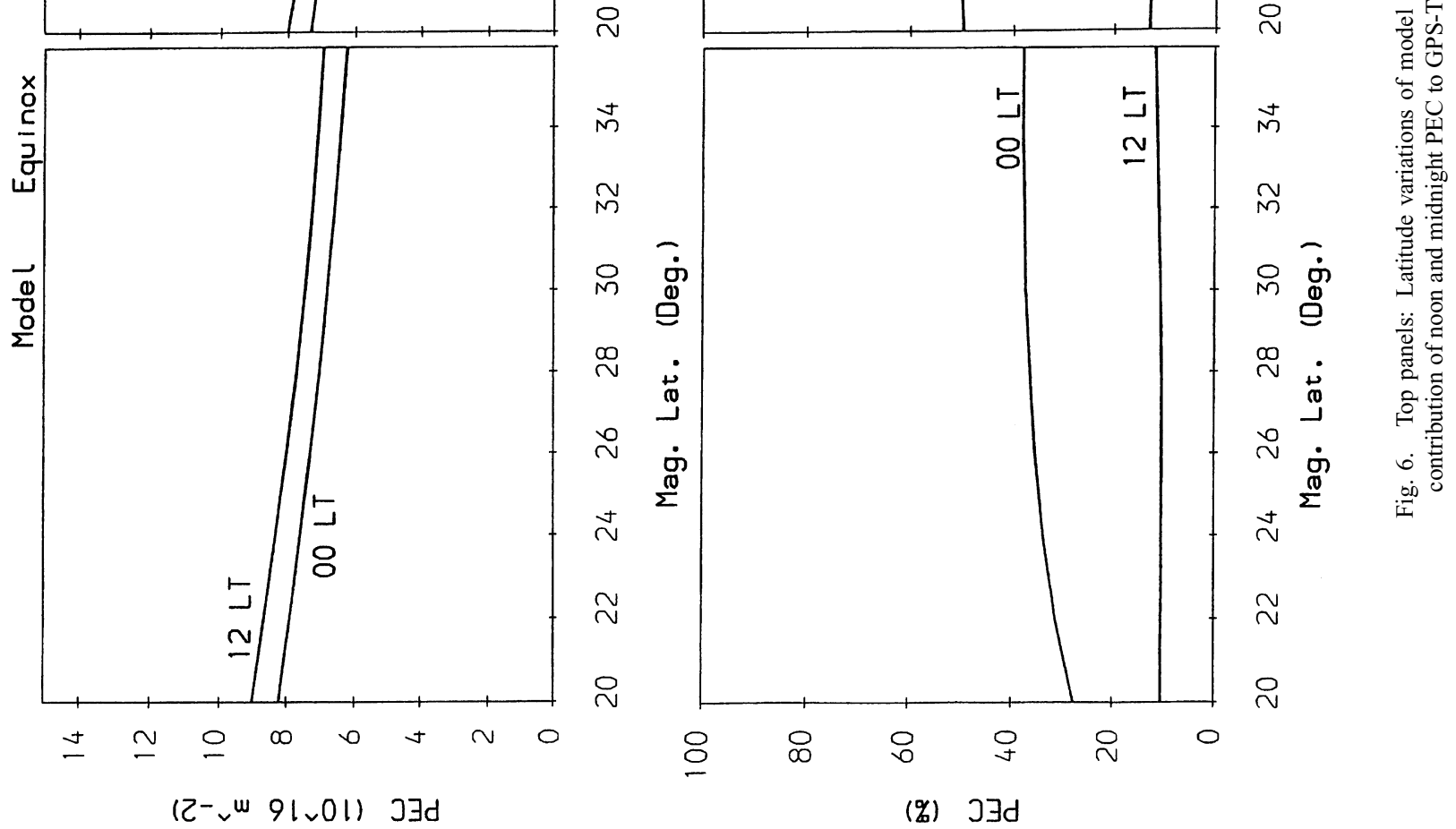
of PEC.

Recently, Lunt et al. (1999) estimated the plasmaspheric electron content in GPS ray paths at altitudes above $1100 \mathrm{~km}$ in the European and American sectors during magnetically quiet periods at low and high solar activities. According to their estimates, the European sector contains up to 4 TEC units of vertical PEC at $40^{\circ} \mathrm{N}$ latitude at very high solar activity $(\mathrm{F} 10.7=250)$ while the American sector has only about half of that due to the tilt of the geomagnetic field. The present estimates of PEC over the northern end of Japan agrees reasonably with those over Europe.

The estimates of PEC presented above are for the vertical sections of GPS ray paths over Japan. The content in the slant plasmaspheric sections can be obtained by multiplying the vertical content (PEC) by appropriate geometrical factors, which can give correct values if the dependence of PEC on latitude (Fig. 6) is also taken care of in the conversion; PEC does not change much in the small $10^{\circ}$ longitude range of Japan. A value of 2 TEC units should be subtracted from the PEC estimates given in Figs. 5 and 6 for approximate determinations of PEC at altitudes above the upper altitude of Faraday rotation.

\section{Summary}

Absolute values of TEC derived from the carrier phase delays and pseudoranges of the GPS signals $(1.57542 \mathrm{GHz}$ and $1.22760 \mathrm{GHz}$ ) recorded by the GEONET in Japan are compared with those calculated using SUPIM. The model is then used to calculate the values of TEC up to GPS altitude and ionospheric electron content, IEC, up to the base of the plasmasphere, which, in turn, are used to estimate PEC (=TEC-IEC). The estimates are made for the three seasons during high solar activity $(\mathrm{F} 10.7=165)$ and under magnetically quiet conditions. According to the estimates, the plasmaspheric section of vertical GPS ray paths over Japan at altitudes above the $\mathrm{O}^{+}-\mathrm{H}^{+}$transition height and above the upper altitude $(2500 \mathrm{~km})$ of Faraday rotation contain up to 11 and 9 TEC units $\left(1\right.$ TEC unit $=10^{16}$ electrons $\left.\mathrm{m}^{-2}\right)$ of free electrons, respectively. The free electrons present above the Faraday rotation altitude can cause propagation errors of up to $4.9 \mathrm{~ns}$ in time delay and $1.6 \mathrm{~m}$ in range at the GPS L1 $(1.57542 \mathrm{GHz})$ frequency.

PEC changes appreciably with season and latitude and very little the with time of the day. Considering all seasons together, PEC above the $\mathrm{O}^{+}-\mathrm{H}^{+}$transition height in the latitude of Japan decreases from a maximum of about 11 TEC units at the southern end $\left(20^{\circ} \mathrm{N}\right.$ mag. lat.) in summer to a minimum of about 5 TEC units at the northern end $\left(36^{\circ} \mathrm{N}\right.$ mag. lat.) in winter, giving an overall annual change of about 6 TEC units. The day-to-night change of PEC is less than 1 TEC unit. However, the percentage contribution of PEC to the GPS-TEC changes from a minimum of about $12 \%$ during daytime at equinox to a maximum of about $60 \%$ at night in winter and before sunrise in summer.

Acknowledgments. GPS data of GEONET were provided by the Geographical Survey Institute of Japan. N. Balan thanks the Solar Terrestrial Environment Laboratory of Nagoya University (Japan) for providing a visiting fellowship.

\section{References}

Bailey, G. J. and N. Balan, A low-latitude ionosphere-plasmasphere model, STEP Handbook, edited by R. W. Schunk, p. 173, Utah State University, 1996.

Bailey, G. J., N. Balan, and Y. Z. Su, The Sheffield University plasmasphere-ionosphere model—a review, J. Atmos. Terr. Phys., 59, 1541, 1997.

Balan, N. and G. J. Bailey, Equatorial plasma fountain and its effects: Possibility of an additional layer, J. Geophys. Res., 100, 21,421-21,431, 1995.

Balan, N., G. J. Bailey, and B. Jayachandran, Ionospheric evidence for a non-linear relationship between the solar EUV and $10.7 \mathrm{~cm}$ fluxes during an intense solar cycle, Planet. Space Sci., 41, 141-145, 1993.

Balan, N., G. J. Bailey, and R. J. Moffett, Modelling studies of ionospheric variations during an intense solar cycle, J. Geophys. Res., 99, 17,467$17,475,1994$

Balan, N., Y. Otsuka, and S. Fukao, New aspects in the annual variations of the ionosphere observed by the MU radar, Geophys. Res. Lett., 24, 2287-2290, 1997.

Balan, N., Y. Otsuka, G. J. Bailey, and S. Fukao, Equinoctial asymmetries in the ionosphere and thermosphere observed by the MU radar, J. Geophys. Res., 103, 9481-9495, 1998.

Carpenter, D. L. and C. G. Park, On what ionospheric workers should know about the plasmapause-plasmasphere, Rev. Geophys., 11, 133-154, 1973.

Chi, P. J., C. T. Russell, S. Musman, W. K. Peterson, G. Le, V. Angelopoulos, G. D. Reeves, M. B. Moldwin, and F. K. Chun, Plasmaspheric depletion and refilling associated with the September 25, 1998 magnetic storm observed by ground magnetometers at $L=2$, Geophys. Res. Lett., 27, 633-636, 2000.

Davies, K., Recent progress in satellite radio beacon studies with particular emphasis on the ATS-6 radio beacon experiment, Space Sci. Rev., 25, $357,1980$.

Doherty, P. H., J. A. Klobuchar, G. J. Bailey, N. Balan, and M. W. Fox, Determinations of protonospheric electron content from TEC measurements from GPS and Faraday rotation and comparisons against the Sheffield plasmasphere model, Proceedings of the International Beacon Satellite Symposium, edited by M. C. Lee, pp. 118-121, Mass. Inst. of Technol., Cambridge, 1992.

Evans, J. V., Satellite beacon contributions to studies of the structure of the ionosphere, Rev. Geophys., 15, 325-350, 1977.

Fejer, B. G., E. R. de Paula, S. A. Gonzales, and R. F. Woodman, Average vertical and zonal $F$ region plasma drifts over Jicamarca, J. Geophys. Res., 96, 13,901, 1991.

Gallagher, D. L., P. D. Craven, and R. H. Comfort, An empirical model of the Earth's plasmasphere, Adv. Space Res., 8, 15-24, 1988.

Hedin, A. E., MSIS-86 thermospheric model, J. Geophys. Res., 92, 4649, 1987.

Hedin, A. E. et al., Revised global model of thermosphere winds using satellite and ground-based observations, J. Geophys. Res., 96, 7657, 1991.

Kersley, L. and J. A. Klobuchar, Comparison of protonospheric electron content measurements from the American and European sectors, Geophys. Res. Lett., 5, 123-126, 1978.

Kersley, L., H. Hajeb-Hossienieh, and K. J. Edwards, Postgeomagnetic storm protonospheric replenishment, Nature, 271, 429-430, 1978.

Kimura, I., K. Tsunehara, A. Hikuma, Y. Z. Su, Y. Kasahara, and H. Oya, Global electron density distribution in the plasmasphere deduced from Akebono wave data and the IRI model, J. Atmos. Solar-Terr. Phys., 59, $1569,1997$.

Kimura, I., Y. Kasahara, and H. Oya, Determination of Global plasmaspheric electron density profile by tomographic approach using omega signals and ray tracing, J. Atmos. Solar-Terr. Phys., 2000 (in press).

Klobuchar, J. A., Ionospheric time-delay algorithm for single frequency GPS users, IEEE Trans. Aerosp. Electron. Syst., AES-23, 325-331, 1987.

Lanyi, G. E. and T. Roth, A comparison of mapped and measured total electron content using Global Positioning System and beacon satellite observations, Radio Sci., 23, 483, 1988.

Lunt, N., L. Kersley, and G. J. Bailey, The influence of the protonosphere on GPS observations: Model simulations, Radio Sci., 34, 725-732, 1999.

Ogawa, T., K. Sinno, M. Fujita, and J. Awaka, Severe disturbances of VHF and $\mathrm{GHz}$ waves from geostationary satellites during a magnetic storm, $J$. Atmos. Terr. Phys., 42, 637-644, 1980.

Oliver, W. L., M. Yamamoto, T. Takami, S. Fukao, M. Yamamoto, and 
T. Tsuda, Middle and Upper Atmosphere Radar observations of ionospheric electric fields, J. Geophys. Res., 98, 11,615, 1993.

Otsuka, Y. et al., A new technique for mapping of total electron content using GPS network in Japan, Earth Planets Space, 54, this issue, 63-70, 2002.

Richards, P. G. and D. G. Torr, Ratios of photoelectron to EUV ionization rates for aeronomic studies, J. Geophys. Res., 93, 4060, 1988.

Rishbeth, H. and C. S. G. K. Setty, The F-layer at sunrise, J. Atmos. Terr. Phys., 20, 263, 1961.

Saito, A., S. Fukao, and M. Miyazaki, High resolution mapping of TEC perturbations with the GSI GPS network over Japan, Geophys. Res. Lett., 25, 3079-3083, 1999.
Titheridge, J. E., Determination of ionospheric electron content from the Faraday rotation of geostationary satellite signals, Planet. Space. Sci., 20, 353, 1972.

Titheridge, J. E., The electron content of the southern mid-latitude ionosphere 1965-1971, J. Atmos. Terr. Phys., 35, 981, 1973.

Tobiska, W. K., Revised solar extreme ultraviolet flux model, J. Atmos. Terr. Phys., 53, 1005, 1991.

N. Balan (e-mail: balan@pspace.sci.hokudai.ac.jp), Y. Otsuka, T. Tsugawa, S. Miyazaki, T. Ogawa, and K. Shiokawa 